\title{
Microspectrophotometric DNA analysis in ulcerative colitis with special reference to its application in diagnosis of carcinoma and dysplasia
}

\author{
K Suzuki, T Muto, T Masaki, Y Morioka
}

\begin{abstract}
The deoxyribonucleic (DNA) content was measured by microspectrophotometry in 100 specimens from 60 patients with ulcerative colitis, including six patients in whom the colitis was associated with carcinoma. Some 23 of $30(77 \%)$ specimens of dysplastic tissue showed aneuploidy or polyploidy, whereas $\mathbf{5 0}$ of $53(94 \%)$ specimens of non-dysplastic tissue showed diploidy. The difference was statistically significant $(p<0 \cdot 001)$. Polyploidy was often observed in non-dysplastic mucosa from patients who had carcinoma or dysplasia. In the non-dysplastic patients all samples of inflamed tissue showed diploidy. Some $10 \%$ of samples without inflammation, however, also showed polyploidy. A good correlation was found between the frequency of polyploid cells and the grade of dysplasia. Microspectrophotometric measurement of DNA content proved useful in the assessment and diagnosis of dysplasia in ulcerative colitis and could be considered for screening high risk patients.
\end{abstract}

The risk of colorectal carcinoma in patients with longstanding ulcerative colitis has been well established. At one time prophylactic proctocolectomy was recommended for those with total colonic involvement and more than 10 years' history of colitis. In 1967 Morson and Pang suggested that the presence of epithelial dysplasia in the rectal biopsy specimen might help to identify high risk patients. ${ }^{1}$ A prospective study has been started at St Mark's Hospital, London, to determine whether high risk patients can be safely followed up by regular colonoscopic biopsy to detect dysplasia as an alternative to prophylactic surgery. ${ }^{2}$

Dysplasia in ulcerative colitis is defined as an unequivocal neoplastic change in the colonic epithelium. ${ }^{3}$ A dysplastic lesion is macroscopically detectable as a polypoid or plaque-like lesion, but it also develops in flat mucosa. ${ }^{4}$

Dysplasia used to be graded as mild, moderate, and severe, as in colonic adenoma. But in recent years the Dysplasia Morphology Study Group has recommended a new classification of dysplasia as negative, indefinite, low grade, and high grade. ${ }^{3}$ The group has formulated guidelines for the clinical management of high risk patients. In this study dysplasia was graded according to this classification.

Recent studies on dysplasia have shown the following unresolved problems ${ }^{5-7}$ :

(1) The classification of dysplasia is subject to inter- and intraobserver variation;
(2) Interpretation is particularly difficult where there is acute inflammation.

Solving these problems has prompted a search for more objective methods of determining dysplasia such as the analysis of DNA content. ${ }^{8}$

In Japan, the frequency of carcinoma in patients with ulcerative colitis has tended to increase in recent years and about 60 cases were reported up to 1989 . There are, however, only a few reports of dysplasia and no reports of DNA abnormality in ulcerative colitis.

In 1987 a prospective microspectrophotometric DNA study of patients with longstanding ulcerative colitis was begun at this hospital. We present the results of this study together with the results from a retrospective study before 1986 and compare the outcome with the experience from western countries.

\section{Methods}

\section{PATIENTS}

One hundred colonic specimens from 60 patients with ulcerative colitis were studied (Table I). There were 36 men and 24 women with a mean age of $42 \cdot 1$ years and a mean disease history of $9 \cdot 6$ years. Thirty six samples from 10 patients were collected from surgically resected specimens at Tokyo University Hospital between 1978 and 1987. The remaining 64 samples were biopsy specimens from 50 patients attending the same hospital between 1986 and 1988. These 64 included 58 biopsy specimens analysed prospectively since 1987 . Some 38 of 56 patients with total (34) or with left-sided (22) colitis who had had colitis for more than seven years underwent annual colonoscopy with biopsy specimens taken every $10 \mathrm{~cm}$.

A total of 30 sections were taken from six patients who had colitis associated with carcinoma. Eight of the 30 showed carcinoma, six showed high grade and 11 low grade dysplasia, and five were of histologically normal mucosa. A diagnosis of displasia was indefinite in four patients, and in these patients sections were also sampled from the normal background mucosa and a coincidental adenoma. The nondysplastic colitis patients were divided into two groups, active colitis (21) and inactive colitis (25).

\section{PREPARATION OF SAMPLES}

All the tissue samples were fixed in $10 \%$ formalin; embedded in paraffin wax; and serial sections 3, 7 , and $100 \mu \mathrm{m}$ were cut consecutively. The $3 \mu \mathrm{m}$ sections were stained with haematoxylin 
TABLE I Findings in 100 colonic specimens from 60 patients with ulcerative colitis

\begin{tabular}{|c|c|c|c|c|c|c|c|c|c|}
\hline \multirow{2}{*}{$\begin{array}{l}\text { Main } \\
\text { finding }\end{array}$} & \multirow[b]{2}{*}{$(\mathrm{No})$} & \multicolumn{8}{|c|}{ Specimen findings } \\
\hline & & $\mathrm{Ca}$ & $H G D$ & $L G D$ & Back & $I N D$ & Inactive & Active & Adenoma \\
\hline $\begin{array}{l}\mathrm{Ca} \\
\text { HGD } \\
\text { LGD } \\
\text { IND } \\
\text { Active } \\
\text { Inactive }\end{array}$ & $\begin{array}{l}(6) \\
(2) \\
(2) \\
(4) \\
(21) \\
(25)\end{array}$ & 8 & $\begin{array}{l}6 \\
1\end{array}$ & $\begin{array}{r}11 \\
2 \\
2\end{array}$ & $\begin{array}{l}5 \\
4 \\
1 \\
1\end{array}$ & $\begin{array}{l}1 \\
4\end{array}$ & $\begin{array}{r}4 \\
26\end{array}$ & 23 & 1 \\
\hline Total & $(60)$ & 8 & 7 & 15 & 11 & 5 & 30 & 23 & $1(100)$ \\
\hline
\end{tabular}

$\mathrm{Ca}=$ carcinoma $\mathrm{HGD}=$ high grade dysplasia $\mathrm{LGD}=$ low grade dysplasia $; \mathrm{Back}=$ background mucosa; IND =indefinite for dysplasia.

and eosin for histopathological examination. The $7 \mu \mathrm{m}$ sections were used for in situ measurement of DNA. The $100 \mu \mathrm{m}$ sections were dewaxed in xylene, digested with $0.5 \%$ pepsin in $0.9 \% \mathrm{NaCl}$ at $\mathrm{pH} 1.5$ and $37^{\circ} \mathrm{C}$ for 30 minutes, and were then processed by Hedley et al's method.' An ultrasonicator Sonifier 250 (Branson, USA) was used to obtain a suspension of cell nuclei. This was smeared on glass slides with Autosmear CF-12C (Sakura Seiki, Japan). The smears and $7 \mu \mathrm{m}$ sections were stained with $0.02 \%$ azocarmin $\mathrm{G}$ for 90 seconds in order to block non-specific fluorescence using the method of Takamatsu. ${ }^{10}$ They were subsequently stained by the $0.001 \%$ acriflavin-Feulgen for 10 minutes.

\section{MICROSPECTROPHOTOMETRY}

DNA analysis was performed using an Olympus microfluorometer AH-2 QRFL (Olympus Co Ltd, Tokyo, Japan). The nuclei stained with acriflavin emit a yellow fluorescence $(520 \mathrm{~nm})$ when excited with a blue light $(437 \mathrm{~nm})$. A set of excitation filter, dichroic mirror, and barrier filter were selected for this purpose.
The DNA content was analysed in $7 \mu \mathrm{m}$ sections initially and then, where aneuploid cells were detected, in smears. All but overlapping or fragmentary nuclei in the sections were measured at random. To determine the DNA ploidy patterns in sections, properly cut mitotic cells were selectively measured because they were considered to contain almost whole amounts of nuclear DNA. " More than 50 or 100 nuclei were measured at random in the sections or in the smears respectively. Twenty lymphocytes were measured in each specimen to define 2c DNA content as a control.

\section{DEFINITION AND STATISTICS}

The DNA peak was defined as diploid when it deviated less than $20 \%$ from the standard lymphocyte peak. It was classified as aneuploid when the major peak of the DNA histogram

TABLE II Ploidy patterns in 100 specimens from 60 patients with ulcerative colitis

\begin{tabular}{|c|c|c|c|c|c|c|}
\hline \multirow[b]{2}{*}{ Histopathology } & \multirow{2}{*}{$\begin{array}{l}\text { No of } \\
\text { samples }\end{array}$} & \multicolumn{3}{|c|}{ Ploidy } & \multirow{2}{*}{$\underset{(\%)}{A \text { or } P}$} & \multirow{2}{*}{$\begin{array}{l}\text { Over } 6 c \\
(\%)\end{array}$} \\
\hline & & $A$ & $D+P$ & $D$ & & \\
\hline $\mathrm{Ca}$ & 8 & 4 & 4 & & 100 & $10 \cdot 3$ \\
\hline HGD & 7 & 4 & 2 & 1 & 86 & $7 \cdot 0$ \\
\hline LGD & 15 & 2 & 7 & 6 & 60 & $3 \cdot 3$ \\
\hline IND & 5 & 1 & 1 & 3 & 40 & $2 \cdot 4$ \\
\hline Back & 11 & & 4 & 7 & 36 & $2 \cdot 5$ \\
\hline Inactive & 30 & & 3 & 27 & 10 & 1.0 \\
\hline Active & 23 & & & 23 & 0 & 0.3 \\
\hline Adenoma & 1 & & & 1 & 0 & 0 \\
\hline Total or mean & 100 & 11 & 21 & 68 & 32 & $2 \cdot 6$ \\
\hline
\end{tabular}

$\mathrm{A}=$ aneuploidy; $\mathrm{D}+\mathrm{P}=$ diploidy + polyploidy $; \mathrm{D}=$ diploidy; $\mathrm{Ca}=$ carcinoma; $\mathrm{HGD}=$ high grade dysplasia; $\mathrm{LGD}=$ low grade dysplasia; IND=indefinite for dysplasia; $B$ ack = background mucosa.
Figure 1: Histopathology and corresponding $D N A$ histogram measured on a $7 \mu \mathrm{m}$ section of a specimen taken from a 53 year old man with a 7 year history of total colitis. (a) High grade dysplasia associated with polypoid lesion in the rectum. (b) DNA histogram of $(a)$ showing aneuploid pattern. (c) Flat mucosa adjacent to lesion showing low grade dysplasia. (d) DNA histogram of $(c)$ showing diploidy.
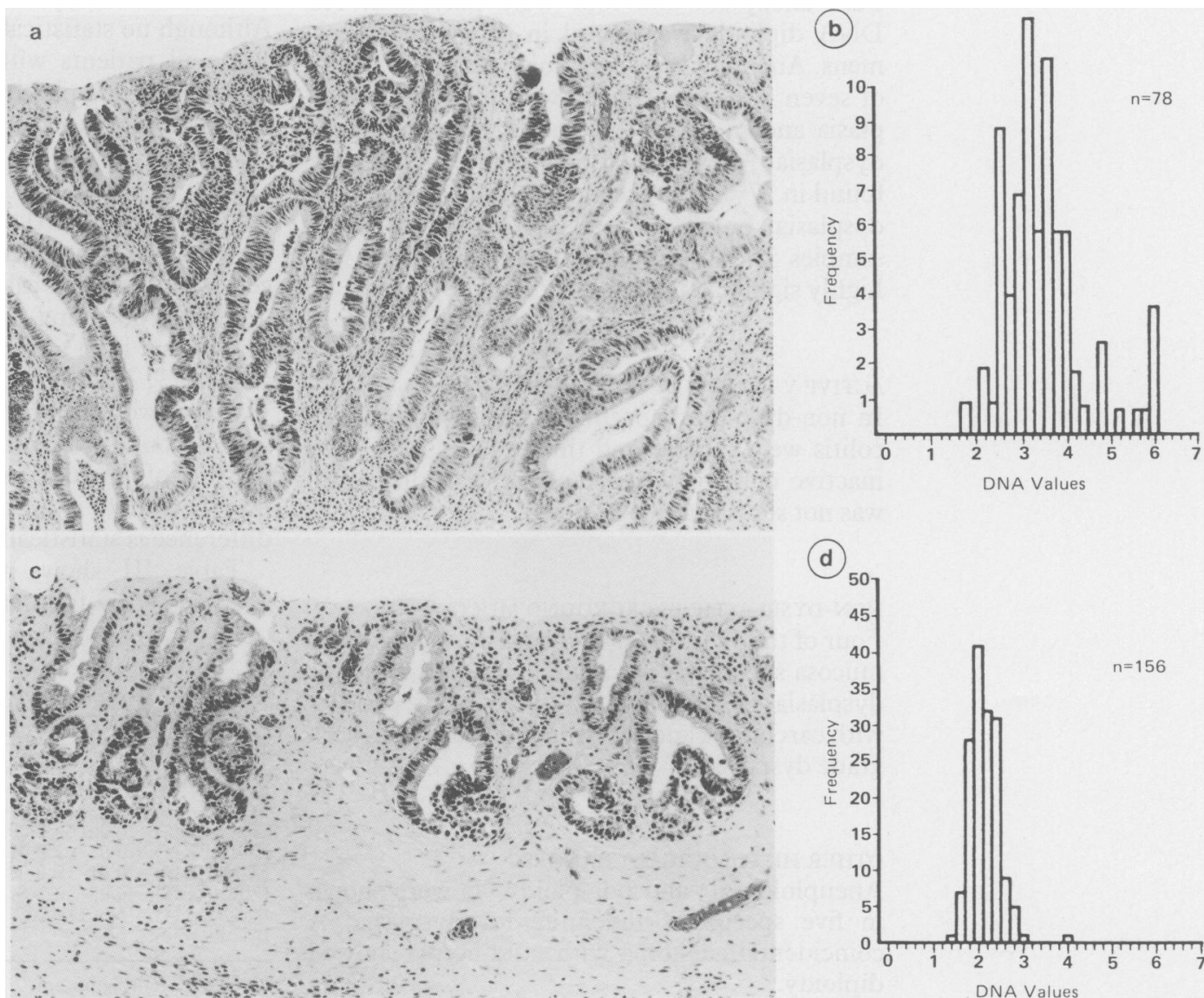
deviated more than $20 \%$ from $2 c$. DNA polyploidy was defined as DNA diploidy with the presence of more than one nucleus of over $6 c$ DNA values.

In this study DNA ploidy was judged according to the results of the smear method, but in the calculation of the frequency of polyploid cells, we adopted the mean values of the smears and sections from the same samples.

The relation between DNA ploidy and the histopathology was analysed with the $\chi^{2}$ test. The frequencies of polyploid cells were compared between groups using the non-parametric Wilcoxon rank sum test. A value of $p<0.05$ was considered to be statistically significant.

\section{Results}

\section{CASE REPORT}

An example of the histopathology and corresponding DNA histogram measured on a $7 \mu \mathrm{m}$ section is shown in Figure 1. Figure 1(a) shows high grade dysplasia associated with a polypoid lesion in the rectum of a 53 year old man with a seven year history of total colitis. Figure 1(b) shows an aneuploid pattern with a peak of 3.2c. The flat mucosa adjacent to the lesion is shown in Figure 1(c). Histopathology was graded as low grade dysplasia. Crypts show depleted goblet cells, crowding, and hyperchromasia of nuclei confined to its basal half. The DNA histogram of this lesion shows diploidy with a peak around $2 \mathrm{c}$ (Fig 1(d)).

CARCINOMA, DYSPLASIA V NON-DYSPLASTIC TISSUE The ploidy patterns of the 100 lesions are shown in Table II. Four of eight carcinoma specimens were aneuploid and four were polyploid. No DNA diploidy was found in carcinoma specimens. Aneuploidy or polyploidy was found in six of seven $(86 \%)$ specimens with high grade dysplasia and in nine of $15(60 \%)$ with low grade dysplasia. Aneuploid or polyploid patterns were found in $77 \%$ of 30 specimens with carcinoma or dysplasia, but $94 \%$ of 53 non-dysplastic tissue samples showed diploidy (the difference was highly significant, $\mathrm{p}<0.001)$.

\section{ACTIVE V INACTIVE COLITIS}

In non-dysplastic specimens, all 23 with active colitis were diploid and three of $30(10 \%)$ with inactive colitis were polyploid. The difference was not statistically significant.

NON-DYSPLASTIC BACKGROUND MUCOSA

Four of the 11 (36\%) non-dysplastic background mucosa specimens associated with carcinoma or dysplasia were polyploid, three from patients with carcinoma and one from a patient with high grade dysplasia.

\section{OTHER HISTOLOGICAL CHANGES}

Aneuploidy (1) and polyploidy (1) were shown in five specimens indefinite for dysplasia. A coincidental adenoma with mild atypia showed diploidy.

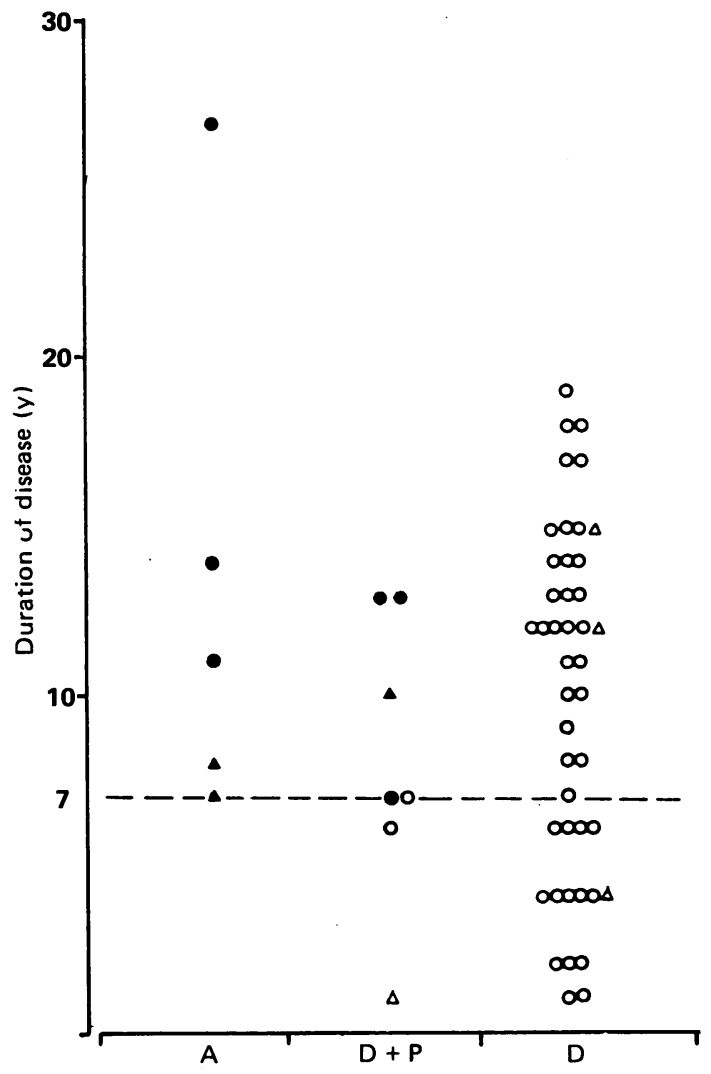

Figure 2: Relation between DNA ploidy and disease duration in 56 patients with ulcerative colitis. $A=$ aneuploidy; $D+P=$ diploidy + polyploidy; $D=$ diploidy; $\mathbf{O}=$ carcinoma $; \mathbf{\Lambda}=$ low or high grade dysplasia; $\triangle=$ indefinite for dysplasia; $\mathrm{O}=$ negative for dysplasia.

\section{DURATION OF DISEASE}

The relation between DNA ploidy and the duration of disease in 56 patients with ulcerative colitis (excluding proctitis) is shown in Figure 2. Although no statistically significant difference is seen, all patients with aneuploidy and five of seven with polyploidy were found to have had colitis for more than seven years.

\section{FREQUENCY OF POLYPLOIDY}

The ratio of polyploid cells to the total number of cells counted was calculated for 99 specimens (except an adenoma) (Fig 3). The mean ratios for carcinoma, high grade, and low grade dysplasia were $10 \cdot 3,7 \cdot 0$, and $3 \cdot 3 \%$ respectively (Table II). Twenty two of $30(73 \%)$ samples of dysplastic tissues contained more than $2 \%$ polyploid cells. Only 3 of $53(6 \%)$ non-dysplastic specimens, however, had a ratio greater than $2 \%$. The difference is statistically significant $(\mathrm{p}<0.001)$.

Table III shows the results of statistical analysis of the frequencies of polyploid cells in

TABLE III Statistical analysis of frequencies of polyploid cells in the different groups

\begin{tabular}{|c|c|c|c|c|c|c|c|}
\hline Samples & (No) & $\begin{array}{l}\text { Active } \\
\text { (23) }\end{array}$ & $\begin{array}{l}\text { Inactive } \\
(30)\end{array}$ & $\begin{array}{l}\text { Back } \\
\text { (II) }\end{array}$ & $\begin{array}{l}I N D \\
(5)\end{array}$ & $\begin{array}{l}L G D \\
(15)\end{array}$ & $\begin{array}{l}\underset{\text { (7) }}{H G D} \\
\text { (1) }\end{array}$ \\
\hline $\begin{array}{l}\text { Ca } \\
\text { HGD } \\
\text { LGD } \\
\text { IND } \\
\text { Back } \\
\text { Inactive }\end{array}$ & $\begin{array}{r}(8) \\
(7) \\
(15) \\
(5) \\
(11) \\
(30)\end{array}$ & $\begin{array}{l}<0.001^{\star} \\
<0.01 \\
<0.01 \\
<0.05 \\
\text { NS } \\
\text { NS }\end{array}$ & $\begin{array}{c}<0.001 \\
<0.01 \\
<0.05 \\
\text { NS } \\
\text { NS }\end{array}$ & $\begin{array}{c}<0.01 \\
\text { NS } \\
\text { NS } \\
\text { NS }\end{array}$ & $\begin{array}{c}<0.05 \\
\text { NS } \\
\text { NS }\end{array}$ & $\begin{array}{c}<0.01 \\
\text { NS }\end{array}$ & NSt \\
\hline
\end{tabular}

${ }^{\star} \mathrm{p}<0.001 ;$ fnot significant. 
TABLE IV Published data on DNA aneuploidy with regard to histological changes

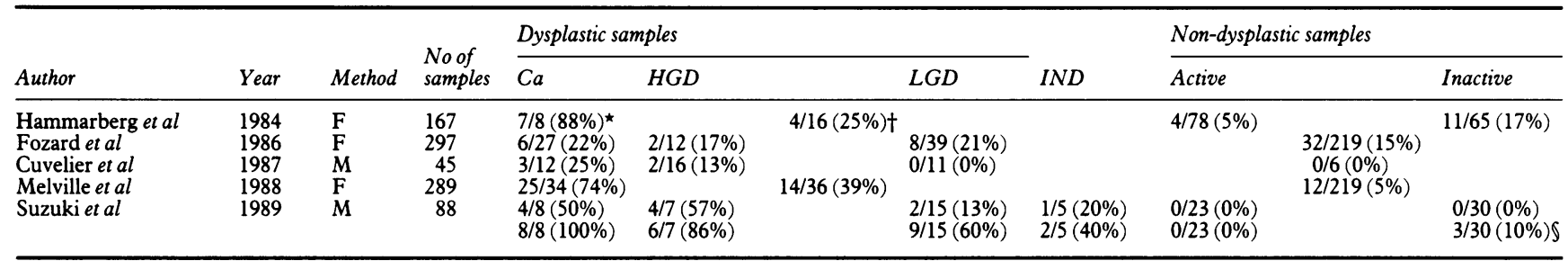

$\mathrm{F}=$ flow cytometry; $\mathrm{M}=$ microspectrophotometry; $\mathrm{Ca}=$ carcinoma; $\mathrm{HGD}=$ high grade dysplasia; $\mathrm{LGD}=$ low grade dysplasia; IND=indefinite for dysplasia. ${ }^{\star}$ The number of samples with aneuploidy in the numerator and the total number of carcinoma samples in the denominator; tincluding high and low grade dysplasia; Sincluding aneuploidy and polyploidy.

the different groups using non-parametric Wilcoxon rank sum test.

\section{Discussion \\ Microspectrophotometric DNA analysis of sectioned samples (section method) allows in situ measurement of DNA by selecting the nuclei in a certain restricted lesion. ${ }^{12}$ In this regard the section method has considerable advantages over flow cytometry and smear method in resolving the problems mentioned previously. It has been considered unreliable, however, because of its lack of accuracy and the limited number of cells measured when compared with the latter method. To compare accuracies we measured the DNA content of the sections and smear cells detatched from the paraffin embedded tissues in the same specimens, and confirmed that the modal DNA values of two methods were quite similar (unpublished data).}

The published data on DNA aneuploidy pre-

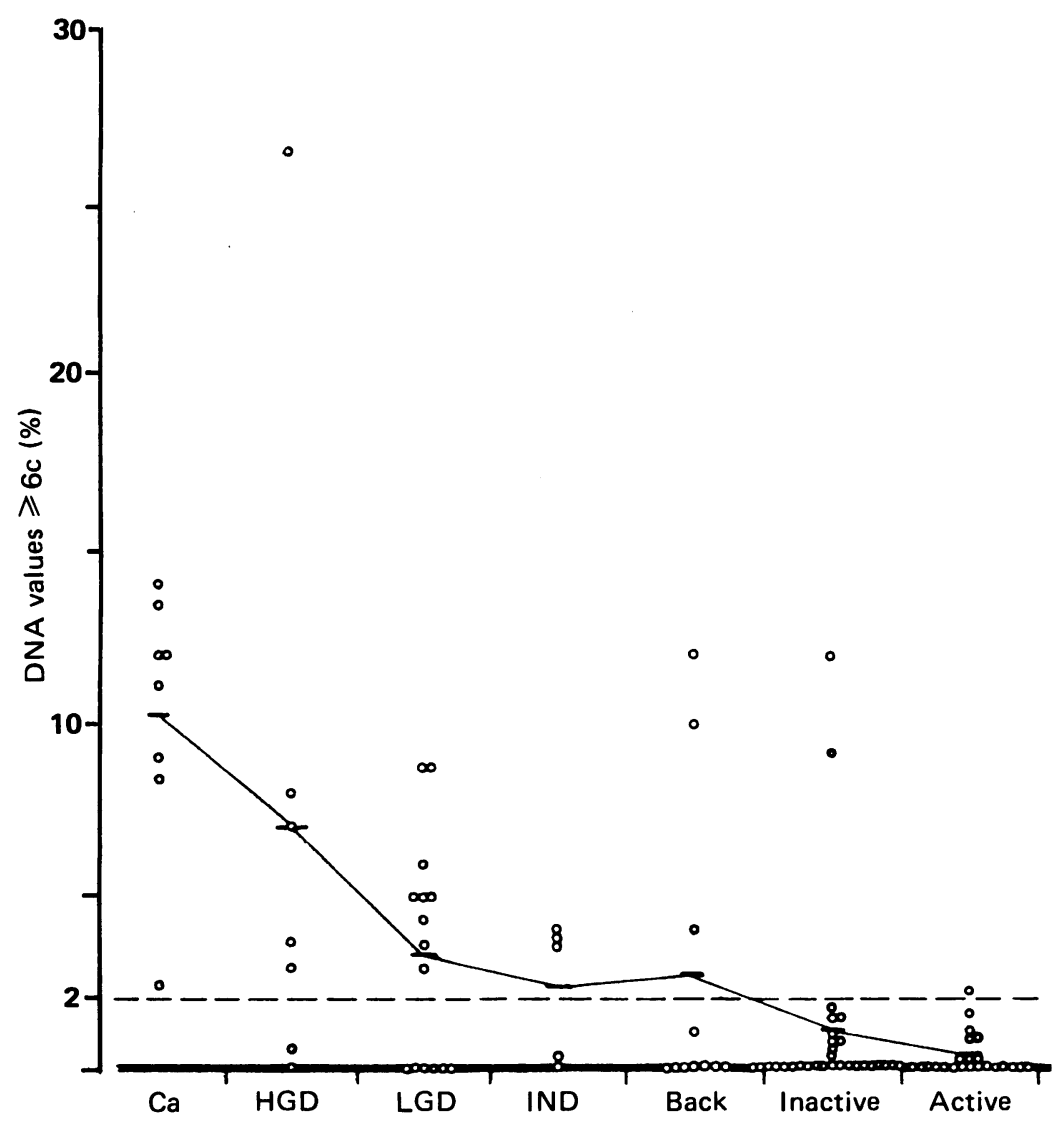

Figure 3: Ratio of polyploid cells to total number of cells counted in 99 specimens from patients with active and inactive ulcerative colitis. $C a=$ carcinoma; $H G D=$ high grade dysplasia; $L G D=$ low grade dysplasia $;$ IND = indefinite for dysplasia. Back=normal background mucosa. valence with regard to histological changes are summarised in Table IV. ${ }^{812-14}$ The prevalence of DNA aneuploidy in carcinoma specimens ranged from 22 to $88 \%$. Fozard et al reported the lowest prevalence $(22 \%)$ from the highest number of colitic samples. The prevalence was $50 \%$ in our current study which is an intermediate value among the published data. There are certain problems to be solved with these different data. Firstly, more data will be needed before the true incidence becomes clear. Secondly, these discrepancies may be due to the different techniques and the criteria employed in diagnosing dysplasia and aneuploidy. ${ }^{15}{ }^{16}$ Because flow cytometry and microspectrophotometry define aneuploidy from different standpoints, it may be difficult to compare results without performing a comparative study using both techniques on the same samples.

We noted that sensitivity to detect malignancy increased when aneuploidy and polyploidy were included. In this study, $77 \%$ of 30 dysplastic specimens, including carcinoma and dysplasia, were DNA aneuploid or polyploid, whereas $6 \%$ of 53 non-dysplastic samples were DNA polyploid (statistically significant). This indicates that microspectrophotometric DNA aneuploidy or polyploidy is highly suggestive of malignancy, as has been shown by some authors using flow cytometry. ${ }^{81317}$ Moreover, our data clearly showed that the frequency of aneuploidy or polyploidy increased from 60 to $100 \%$ with the increasing grade of dysplasia, suggesting that microspectrophotometric DNA analysis could be used as a supplementary aid in the diagnosis of dysplasia in ulcerative colitis. It is also interesting to note that the higher the grade of dysplasia, the higher the frequency of polyploid cells. In this regard polyploidy was considered to be an intermediate phase between aneuploidy and diploidy.

There are few reports on polyploid cells in DNA analysis of dysplasia in ulcerative colitis because of the general use of flow cytometry in western countries. Only Cuvelier $e t a l^{12}$ reported that the spectrum of precancerous lesions showed a gradual transition from normal diploid distributions in low grade dysplasia to polyploid and abnormal aneuploid distributions in high grade dysplasia. The results of our study also showed a similar trend (Table II).

The distribution of the percentage of polyploid cells in the total number of cells measured is interesting. The mean values of carcinoma, high grade, and low grade dysplasia were $10 \cdot 3$, $7 \cdot 0$, and $3 \cdot 3 \%$ respectively, and $73 \%$ of 30 dysplastic samples had the over $6 \mathrm{c}$ polyploidy 
frequency of more than $2 \%$ as compared with only $6 \%$ of 53 non-dysplastic specimens (statistically significant, $\mathrm{p}<0.001$ ). Therefore, this $2 \%$ ratio for polyploidy frequency was considered to be a marker for the presence of dysplasia. A statistical study using the non-parametric Wilcoxon rank sum test was undertaken to determine the significant differences between various groups. As shown in Table III, the more separate from each other in the spectrum of dysplasia the groups were, the more significant the difference between the groups. These results indicate that the percentage of polyploid cells could be useful for the diagnosis of dysplasia.

Among non-dysplastic specimens, $10 \%$ of the specimens in the inactive phase were polyploid while all those in the active phase were diploid. Hammarberg et al also reported that much larger numbers of specimens were aneuploid in the inactive phase than in the active phase (Table IV). ${ }^{8}$ Further studies may be necessary before the clinical implications of these findings become clear. Since all the non-dysplastic active samples were diploid, however, and as the active phase did not disturb the DNA measurement in the diagnosis of dysplasia, we believe that microspectrophotometric analysis may be helpful in discriminating true dysplasia from inflammatory reactive change. ${ }^{18}$

The presence of aneuploidy in specimens that were indefinite for dysplasia and polyploidy in specimens indefinite for dysplasia, background mucosa, and inactive mucosa needs further explanation for clinical application. Although the presence of polyploidy suggests premalignant change or at least change towards malignancy on a DNA level, it is not clear yet whether this change is irreversible and will definitely lead to a clinically malignant condition in the future. As normal cells do not usually show polyploidy we consider that the colon which contains polyploid cells is abnormal, and patients are put on a close surveillance programme to see the long term outcome as far as developing overt dysplasia is concerned. In particular, patients with specimens indefinite for displasia that show aneuploidy or polyploidy are being kept under close observation.

In conclusion, our current results clearly show the usefulness of microspectrophotometric DNA analysis as a supplementary tool in the diagnosis of dysplasia in patients with long- standing ulcerative colitis. Furthermore, this technique may be able to detect much earlier precancerous change on a DNA level, even in non-dysplastic normal looking mucosa. ${ }^{1920}$ Longterm studies are required, however, to confirm the clinical usefulness of this new method.

This work is financially supported in part by a Grant in Aid for Cancer Research and Scientific Research and by a grant from the Ministry of Welfare.

1 Morson BC, Pang LSC. Rectal biopsy as an aid to cancer control in ulcerative colitis. Gut 1967; 8: 423-34.

2 Lennard-Jones JE, Morson BC, Ritchie JK, et al. Cancer surveillance in ulcerative colitis. Experience over 15 years. Lancet 1983; ii: 149-52.

3 Riddell RH, Goldman H, Ransohoff DF, et al. Dysplasia in inflammatory bowel disease: Standardized classification with provisional clinical applications. Hum Pathol 1983; 14: with pro

4 Riddell $R H$. Dysplasia and cancer in inflammatory bowel disease. BrF Surg 1985; 7 (suppl): 83.

5 Filipe MI, Edwards MR, Ehsanullah $M$. A prospective study of dysplasia and carcinoma in the rectal biopsies and rectal stump of eight patients following ileorectal anastomosis in ulcerative colitis. Histopathology 1985; 9: 1139-53.

6 Collins RH, Feldman M, Fordtran JS. Colon cancer, dysplasia, and surveillance in patients with ulcerative colitis. NEnglf Med 1987; 316: 1654-8.

7 Fozard JBJ, Dixon MF. Colonoscopic surveillance in ulcerative colitis: dysplasia through the looking glass. Gut 1989; tive colitis:

8 Hammarberg C, Slezak P, Ttibukait B. Early detection of malignancy in ulcerative colitis. A flow-cytometric DNA study. Cancer 1984; 53: 291-5.

9 Hedley DW, Friedlander ML, Tayler IW, et al. Method for analysis of cellular DNA content of paraffin-embedded pathological material using flow cytometry. $\mathcal{f}$ Histochem Cytochem 1983; 31: 1333-5.

10 Takamatsu $\mathrm{T}$. Cytofluorometry on cells isolated from parafin sections after blocking of the background fluorescence by azocarmin-G. Histochemistry 1980; 66: 169-80.

11 Hattori T, Hosokawa $Y$, Sugihara $H$, et al. DNA content of diffusely infiltrative carcinoma in the stomach. Pathol Res Pract 1985; 180: 615-8.

12 Cuvelier CA, Morson BC, Roels HJ. The DNA content in cancer and dysplasia in chronic ulcerative colitis. Histopathology 1987; 11: 927-39.

13 Melville DM, Jass JR, Shepherd NA, et al. Dysplasia and deoxyribonucleic acid aneuploidy in the assessment of precancerous changes in chronic ulcerative colitis. Observer variation and correlations. Gastroenterology 1988; 95: 668-

14 Fozard JBJ, Quirke P, Dixon MF, et al. DNA aneuploidy in ulcerative colitis. Gut 1986; 27: 1414-8.

15 Fozard JBJ, Quirke P, Dixon MF. DNA aneuploidy in ulcerative colitis. Gut 1987; 28: 642-3.

16 Melville DM, Northover JMA, Jass JR, et al. DNA aneuploidy in ulcerative colitis. Gut 1987; 28 : 643.

17 Winkelmann M, Pfitzer P, Schneider W. Significance of polyploidy in megakaryocytes and other cells in health and polyploidy in megakaryocytes and other cells in health

18 Löberg R, Tribukait B, Ost A, et al. Flow cytometric DNA analysis in longstanding ulcerative colitis: a method of prediction of dysplasia and carcinoma development? $G u$ 1987; 28: 1100-6.

19 Rutegird J, Ahsgren L. Stenling R, et al. DNA content in ulcerative colitis. Dis Colon Rectum 1988; 31: 710-5.

20 Hammarberg C, Rubio C, Slezak P, et al. Flow-cytometric DNA analysis as a means for early detection of malignancy in
patients with chronic ulcerative colitis. Gut 1984; 25: $905-8$. 